\title{
AÇÕES EM MARKETING SOCIAL DO PONTO DE VISTA DA LÓGICA DOMINADA PELO SERVIÇO: O CASO DO PROGRAMA "O JOVEM E A MOBILIDADE"
}

\author{
ACTIONS IN SOCIAL MARKETING FROM THE PERSPECTIVE OF SERVICE-DOMINATED LOGIC: THE \\ CASE OF THE "O JOVEM E A MOBILIDADE" PROGRAM
}

ACCIONES EN MARKETING SOCIAL DESDE EL PUNTO DE VISTA DE LA LÓGICA DOMINANTE DEL SERVICIO: EL CASO DEL PROGRAMA "EL JOVEN Y LA MOVILIDAD"

\author{
AGNALDO KEITI HIGUCHI \\ Doutorando \\ Universidade Federal de Minas Gerais - Brasil \\ agnson@ibest.com.br \\ NATALINA ALICE COUTO DIMEIRA \\ Especialista \\ Empresa de Transportes e Trânsito de Belo Horizonte S/A - Brasil \\ nalice@pbh.gov.br \\ REGINALDO MORAIS DE MACEDO \\ Doutorando \\ Universidade Federal de Minas Gerais - Brasil \\ reginaldom@fasa.edu.br \\ RICARDO TEIXEIRA VEIGA \\ Doutor \\ Universidade Federal de Minas Gerais - Brasil \\ rveiga@ufmg.br
}

Submetido em: 09/12/2014

Aprovado em: 18/08/2015

Doi: alcance.v22n3.426-441

\section{RESUMO}

O marketing social visa promover a qualidade de vida das pessoas, por exemplo, visa convencer pessoas em risco social a adotar voluntariamente comportamentos que tragam segurança e bem-estar, individualmente e coletivamente. Entretanto, normalmente programas de marketing social são elaborados com base na Lógica Dominada pelo Produto (em inglês, 'Good-Dominant Logic", ou seja, GD-L), a qual, segundo Vargo e Lusch (2006, 2010), apresenta várias limitações. Uma delas é não considerar clientes como parceiros, capazes de auxiliar na provisão do serviço, nem como beneficiários que participam na cocriação de valor, auxiliando o provedor do serviço. Para superar essas e outras deficiências, Vargo e Lusch propõem nova perspectiva: a Lógica Dominada pelo Serviço ("Service-Dominant Logic", abreviada, em português, como LDS). Este é um estudo descritivo e qualitativo, no qual o programa social "O Jovem e a Mobilidade" é analisado, adotando-se a LDS como estrutura teórica. Dados obtidos com pesquisa documental e entrevista semiestruturada foram analisados. Resultados mostram que alguns procedimentos do programa remetem a premissas da LDS, por exemplo, a importância atribuída pela coordenadora pedagógica à participação dos alunos na coprodução das atividades evidencia que ela considera os alunos como recursos operantes. Por outro lado, o conteúdo do relatório de atividades do programa revelou-se inteiramente voltado para a LDP, porque destaca a eficiência em vez da eficácia. 
Palavras chave: Lógica Dominada pelo Serviço. Marketing Social. Programa "O Jovem e a Mobilidade". Lógica Dominada pelo Produto.

\begin{abstract}
Social marketing seeks to promote quality of life. For example, it aims to persuade people at social risk to voluntarily adopt behaviors that bring security and well-being, individually and collectively. However, social marketing programs are usually built based on a Good-Dominant Logic (GDL), which has many limitations, according to Vargo and Lusch $(2006,2010)$. One of them is failing to consider customers as partners, capable of helping in the service provision, or as beneficiaries who participate in the co-creation of value, assisting the services provider. In order to overcome these and other limitations, Vargo and Lusch established a new perspective: the Service-Dominant Logic. This is a descriptive and qualitative study in which the social program "O Jovem e a Mobilidade" ("Youth and Mobility") is analyzed, adopting SDL as a framework. Data gathered with desk research and semistructured interview were analyzed. The results show that some procedures of the program are based on the premises of LDS. For example, the importance given by the coordinator to the student's participation in the co-production of activities demonstrates that she regards students as operating resources. Meanwhile, the content of the report is entirely consistent with GDL, giving prominence to efficiency instead of efficacy.
\end{abstract}

Keywords: Service-Dominant Logic. Social Marketing. "Youth and Mobility" social program. Product-Dominant Logic.

\title{
RESUMEN
}

El marketing social tiene el propósito de promover la calidad de vida de las personas, como por ejemplo convencer a las personas que están en riesgo social a adoptar voluntariamente comportamientos que traigan seguridad y bienestar individual y colectivo. Sin embargo, por lo general los programas de marketing social elaborados con base en la Lógica Dominante del Producto (en inglés, "Good-Dominant Logic", o sea GD-L) presentan diversas limitaciones, según Vargo y Lusch $(2006,2010)$. Una de ellas es la de no considerar a los clientes como socios capaces de auxiliar en la provisión del servicio, ni como beneficiarios que participan en la cocreación de valor, auxiliando al proveedor del servicio. Para superar esas y otras deficiencias, Vargo y Lusch proponen una nueva perspectiva: la Lógica Dominante del Servicio ("Service-Dominant Logic", abreviada en español como LDS). Este es un estudio descriptivo y cualitativo, en el cual se analiza el programa social "El Joven y la Movilidad" adoptando la LDS como estructura teórica. Se analizaron los datos obtenidos mediante investigación documental y entrevista semiestructurada. Los resultados muestran que algunos procedimientos del programa remiten a premisas de la LDS, como por ejemplo la importancia que la coordinadora pedagógica atribuye a la participación de los alumnos en la coproducción de las actividades, que evidencia que ella considera a los alumnos como recursos operantes. Por otro lado, el contenido del relato de las actividades del programa reveló estar enteramente orientado hacia la LDP, porque destaca la eficiencia en vez de la eficacia.

Palabras clave: Lógica Dominante del Servicio. Marketing Social. Programa "El Joven y la Movilidad". Lógica Dominante del Producto.

\section{INTRODUÇÃO}

O Marketing Social adota conceitos e ferramentas de marketing tradicional em campanhas promovidas por entidades governamentais ou privadas, com o intuito de gerar uma mudança voluntária no comportamento de pessoas, para que desenvolvam hábitos socialmente apropriados para a convivência em sociedade (ANDREASSEN, 1994). Essas ferramentas de marketing originaram-se da perspectiva da lógica dominada pelos produtos que, entre outras características, considera a proposta de mudança de hábito como serviço, ou seja, produto intangível, que é apresentado ao consumidor potencial para ser assimilada (ou "consumida"), finalizando o ciclo da troca. 
Vargo e Lusch (2006) propõem nova lógica para abordar os fenômenos do marketing, inclusive do Marketing Social, baseada na ideia de que todas as trocas são trocas de serviço por serviço. Essa proposta teórica é denominada Lógica Dominada pelo Serviço (LDS). Nela os autores elaboram proposições fundacionais, tais como: todas as trocas são trocas de serviços; recursos utilizados na coprodução de valor podem ser ativos ou passivos; pagamentos em dinheiro apenas mascaram trocas indiretas de serviço entre atores. Na LDS, a distinção entre produtores e consumidores é abandonada, pois tanto produtores quanto consumidores integram recursos e são corresponsáveis pelo valor criado nas trocas (VARGO; LUSCH, 2006).

Lusch e Vargo são os principais autores citados na literatura que aborda a Lógica Dominada pelo Serviço. Contudo, autores brasileiros vêm também discutindo esse assunto, dentre os quais podem ser destacados: Brambilla e Damacena (2011) analisam os conceitos e premissas da SDL aplicados à educação superior privada na perspectiva docente; Moraes e Costa (2013) analisam a utilização e os impactos da LDS em uma empresa aeronáutica.

Neste trabalho, usuários (que passam a ser atores conforme a LDS) são representados por participantes das ações sociais promovidas pela BHTRANS, órgão público gestor do trânsito da cidade de Belo Horizonte. Mais especificamente, usuários são estudantes do ensino médio das redes estadual e particular participantes do programa "O Jovem e a Mobilidade", o qual visa promover a conscientização do bom comportamento no trânsito. Como programas como este provavelmente tenham sido criados na perspectiva da Lógica Dominada pelos Produtos, devem guardam características deste, e não devem basear-se no pressuposto de que usuários participem da cocriação de valor.

Assim, o objetivo principal deste trabalho é analisar o programa social "O Jovem e a Mobilidade" da BHTRANS, do ponto de vista da Lógica Dominada pelo Serviço. A análise inclui os pontos de interseção do programa social com a Lógica Dominada pelo Produto. Após a análise, propõem-se sugestões embasadas em premissas da Lógica Dominada pelo Serviço, sobre a execução dos processos de coprodução de serviço e de cocriação de valor.

O artigo está estruturado da seguinte forma: inicialmente são apresentadas as premissas básicas da Lógica Dominada pelo Serviço, comparando-as aos fundamentos da Lógica Dominada pelos Produtos; em seguida é definido o foco do marketing social aplicado neste trabalho; em terceiro lugar são expostas as ações de marketing social executadas pela BHTRANS no programa "O jovem e a mobilidade"; em seguida é feita a discussão sobre a conformidade das ações em relação às premissas fundamentais da Lógica Dominada pelo Serviço; por fim, nas considerações finais, são apresentadas limitações do estudo e sugestões para estudos posteriores.

\section{REFERENCIAL TEÓRICO}

\subsection{Diferenças entre a LDS e a LDP}

Em contraste com a até então predominante Lógica Dominada pelos Produtos, a Lógica Dominada pelo Serviço não foca o sistema econômico do ponto de vista da produção-consumo de bens. Lusch e Vargo (2014) postulam que o essencial nas trocas é a troca de serviço por serviço, sendo o serviço um processo em que um ator beneficia outro e/ou tira proveito da interação. Esse processo de servir envolve aplicação de conhecimentos e habilidades, por isso os autores definem serviço como "aplicação de competências (conhecimentos e habilidades) para o benefício de outra entidade ou de si mesma" (LUSCH; VARGO, 2014, p.12).

$\mathrm{Na}$ LDS, o conceito de ator é bem amplo. Atores são entidades que apresentam capacidade de agir orientadas por propósitos, condicionados pela sua própria história, ideologia, experiência e capacidades. Atores, por outro lado, possuem limitações, normalmente impostas por normas, atitudes e outras estruturas compartilhadas. Este conceito de ator faz com que estes superem as limitações das díades como produtorconsumidor, fornecedor-usuário, B2B, B2C, C2C, transformando todos os participantes de uma rede em atores que trocam serviço por serviço no ambiente econômico e social (VARGO; LUSCH, 2006). 
Assim é importante não confundir o conceito "serviço" (termo no singular) da LDS com o conceito de "serviços" empregado na Lógica Dominada pelos Produtos. Na LDP o serviço é visto como bem intangível, caracterizado pela inseparabilidade entre produção e consumo, qualidade heterogênea e impossibilidade de ter a "sobra" estocada. Para superar as dificuldades da gestão de serviços no marketing tradicional, são sugeridas medidas que aumentem a eficiência, por exemplo, padronização de serviços, estratégias para nivelar a demanda à capacidade, etc.

Vargo e Lusch (2006) argumentam que é preciso superar esse conceito de "serviços" focado na criação de valor baseado na produção eficiente. Na LDS, o foco da criação de valor está em parte no consumidor e na interação que fortalece a eficácia da proposta de valor, ou seja, o foco passa da eficiência para a eficácia.

De acordo com a Lógica Dominada pelo Serviço, o serviço é a base de todas as trocas, e os produtos tangíveis têm a função de viabilizar serviços, ou os produtos tangíveis é que são um caso especial da provisão de serviços, porque são "veículos de entrega do serviço"(VARGO; LUSCH, 2006).

Outra implicação da LDS está no papel da especialização. Hunt (2002) observa que a troca é o objeto focal dos estudos de marketing. A troca, por sua vez, é um corolário da divisão do trabalho, uma vez que, ao decorrer da história, as pessoas deixaram de produzir tudo que precisavam para sua subsistência, e passaram a trocar produtos e serviços entre si para sobreviver (HUNT, 2002). A divisão do trabalho, por sua vez, implicou a especialização de tarefas. Especialização implica o refinamento dos recursos operantes, que são pessoas em suas habilidades e conhecimento. Obviamente os recursos operados, como matéria-prima e ferramentas, continuam essenciais, mas para gerar benefícios é preciso conhecimento e habilidades para "encontrar, extrair, cultivar, inventar, fabricar e usar recursos operados, ou seja, os benefícios derivam da aplicação de recursos operantes a recursos operados." (VARGO; LUSCH, 2006, p.45).

Como se pode perceber, o conceito de recurso na LDS difere do utilizado na LDP. Na LDS, recurso é tudo que 0 ator pode utilizar para criar valor. Além disso, os recursos podem ser operáveis e operantes, sendo os primeiros normalmente estáticos e tangíveis, como minério de ferro; e os segundos dinâmicos e intangíveis, como conhecimento e capacidades humanas. É pela aplicação de recursos operantes em recursos operáveis que se gera valor, que na LDS é conceituado como o benefício gerado, e não como o resultado da comparação entre custos e benefícios (LUSCH; VARGO, 2014).

Aprofundando o conceito de valor, na LDS os atores se organizam em redes que se interligam e constantemente se influenciam mutuamente. Valor, nestes sistemas complexos, é igual a um incremento na viabilidade, ou seja, na chance de sobrevivência e bem-estar. Todos os sistemas direcionam suas ações no sentido de aumentar sua viabilidade, por isso a todo momento estão criando valor para outros e para si (WIELAND; POLESE; VARGO; LUSCH, 2012).

As análises de Vargo e Lusch (2008) resultaram em dez premissas fundamentais da LDS, apresentadas a seguir:

-(P1): serviço é a base fundamental da troca;

-(P2): troca indireta encobre a base fundamental de troca;

- (P3): bens são um mecanismo de distribuição de serviços;

-(P4): recursos operantes são a fonte fundamental de vantagem competitiva;

- (P5): todas as economias são economias de serviço;

- (P6): o consumidor é sempre cocriador de valor;

-(P7): a firma não entrega valor, apenas propostas de valor;

- (P8): uma visão centrada em serviço é inerentemente orientada para cliente e relacional;

- (P9): todos os atores, sociais e econômicos, são integradores de recursos;

-(P10): valor é unicamente e fenomenologicamente determinado pelo beneficiário. 
Assim, na LDS, agricultura, atividades extrativas e indústria são formas de provisão de serviço, e prestação de serviços é a aplicação de conhecimento e habilidades que foram extraídos, projetados, gerenciados, financiados, contabilizados e distribuídos. Vargo e Lusch (2006), entretanto, enfatizam que a LDS ordena o serviço acima de produto apenas em termos de classificação e função. Em termos de importância ambos se equivalem, pois o produto é essencial para a entrega do serviço, ou seja, não há um sem o outro.

Vargo e Lusch (2006) enfatizam também que não se deve confundir o atributo de "orientado ao consumidor" da Lógica Dominada pelos Produtos com a SDL. Na orientação ao consumidor da LDP, os produtos são embebidos com valor durante sua fabricação ou extração, e este valor é avaliado pelo consumidor. Mas como citado na premissa P7, o valor não pode ser criado independentemente na manufatura. A LDP corrige este problema ao definir o consumidor como cocriador de valor na experiência de uso ou consumo (premissa P10). Não é preciso fazer uma separação entre valor gerado na produção e valor atribuído no consumo. Na LDS, a orientação para o consumidor se torna redundante (VARGO; LUSCH, 2006).

Outros esclarecimentos são necessários. Primeiramente, é preciso esclarecer que a LDS não é a lógica utilizada por ou criada para as empresas de serviço. A LDS não é feita especialmente para ser aplicada apenas em bancos, hospitais e escolas particulares, porque todas as atividades econômicas correspondem a algum tipo de serviço ou troca de serviço por serviço. Em segundo lugar, o conceito de relacionamento utilizado na LDS é mais amplo. A criação e a manutenção de um relacionamento deixam de ser objetivo somente da firma, para ser uma relação buscada por ambos os cocriadores de valor, os quais entregam e recebem valor na troca (VARGO; LUSCH, 2006).

Em suma, os argumentos de Lusch e Vargo (2014) contestam três pontos da LDP que, segundo eles, limitam um maior entendimento das trocas: (i) a ênfase no produto como resultado ou solução, sendo que a solução está no serviço proporcionado pelo produto; (ii) a atribuição do papel de ator proativo criador de valor somente à firma, sendo que os consumidores participam da coprodução e cocriação de valor ao também realizar a integração de recursos; (iii) a ênfase no valor de troca ou de mercado, sendo que a medida de quanto algo contribui para o bem-estar do ator é o valor de uso. Essas contestações podem levar a reorientações no campo teórico das ciências econômicas e sociais.

Com relação ao impacto da LDS em uma possivel revisão de teorias econômicas e sociais, Vargo e Lusch (2006) mostram-se otimistas. Na economia, os autores observam que Adam Smith, em seu livro "A Riqueza das Nações", aproximou-se muito da LDS quando descreve que após a divisão do trabalho, o homem consegue produzir sozinho, com seu próprio trabalho, apenas parte do que necessita para viver, sendo a maior parte derivada do trabalho alheio. 0 trabalho, portanto, é a medida real de troca de todos os produtos. Se se pensar o trabalho como especialização e conhecimento, tem-se aí a essência de um dos axiomas da LDS.

Sobre um possível impacto nas teorias sociais, a LDS considera que a especialização dos indivíduos em algum tipo de conhecimento e habilidade (que os torna recursos operantes) é fundamental para o bem-estar social. Assim como é fundamental a capacidade de trocar a aplicação destes recursos com outros que possuem outros conhecimentos e habilidades. Vargo e Lusch (2006) exemplificam esta situação utilizando o pescador e 0 fazendeiro que, na verdade, não trocam peixes por verduras entre si. 0 que ocorre de fato é que o pescador pesca para o fazendeiro e fazendeiro cultiva para o pescador.

Para Vargo e Lusch (2006, p.54),

(...) este deslocamento no foco do recurso operado para o operante tem implicações para 0 entendimento da interação social e da estrutura social que difere em muito daquele entendimento sugerido pelo foco na troca de recursos operados, e tem potencialmente ramificações para o entendimento de processos, dinâmicas, estruturas de troca, e de instituições além do comércio.

Entre as instituições, além do comércio, pode-se citar o caso dos órgãos governamentais e das organizações do terceiro setor, que não possuem vínculo com a esfera pública, mas possuem interesses públicos. Normalmente, estas organizações não possuem fins lucrativos e gerenciam recursos com objetivos não financeiros, como o bem-estar social. Entre as ferramentas utilizadas por estes órgãos está o marketing social, cujos fundamentos e definições são expostos no tópico a seguir. 


\subsection{Marketing Social}

O termo Marketing Social foi cunhado por Kotler e Zaltman, em 1971, no artigo "Marketing Social: uma abordagem para a mudança social planejada", referindo-se ao uso de técnicas e ferramentas do marketing com vistas a promover uma causa social, uma ideia ou comportamento, constituindo uma nova área da disciplina de marketing (ZENONE, 2006).

As semelhanças entre o Marketing Social (MS) o Marketing Comercial (MC) são representadas pelos seguintes aspectos: a) foco no cliente; b) a teoria da troca é fundamental; c) uso da pesquisa de marketing é bastante incentivado e necessário; d) os públicos são segmentados; e) o uso do Composto de Marketing em sua plenitude é fundamental; e f) os resultados são mensurados e usados para melhorias (ZENONE, 2006).

As diferenças, por sua vez, ficam por conta dos seguintes pontos: a) no Marketing Social, o objeto é a mudança de um determinado comportamento, ao passo que no MC são produto e/ou serviços; b) no Marketing Social não existe a finalidade de retorno financeiro, diferentemente do Marketing Comercial, que visa à maximização dos retornos financeiros auferidos pelos produtos e/ou serviços; e c) a análise de resultados no MS leva em consideração a eficiência, a eficácia e também a efetividade (análise de impactos em médio e longo prazo), enquanto no MC, normalmente, são consideradas apenas a eficiência e a eficácia (ZENONE, 2006).

Para evitar uma confusão conceitual, é preciso estabelecer uma fronteira entre o Marketing Social e o Marketing Social Corporativo. A diferença básica entre eles é a questão do envolvimento de uma marca associada a uma empresa. No Marketing Social Corporativo, há uma associação entre marca e causa social. Assim, as ações socialmente responsáveis, executadas de acordo com os preceitos da Responsabilidade Social Corporativa, são utilizadas para fortalecer a imagem da marca perante os consumidores. Ou como colocam Pringle e Thompson (2000), para a criação de um "espírito da marca" (brand spirit).

É necessário também diferenciar o Marketing Social do Marketing de Causas, que pode ser compreendido como a associação entre os objetivos organizacionais (melhoria da percepção de um produto e/ou serviço ou da imagem institucional) a uma causa de fundo social. A principal diferença neste caso é a construção do P (Produto): enquanto no Marketing Social o cerne é a mudança do comportamento social, no Marketing de Causas o foco está no produto ou no serviço disponibilizado pela empresa, sendo a ação social mais uma forma de realizar a alavancagem do mesmo (ZENONE, 2006).

A associação com uma causa social e o fortalecimento da imagem da marca perante os consumidores podem trazer benefícios econômicos para a empresa. Principalmente no estrato de consumidores que gostariam de fazer a diferença na sociedade por meio de suas opções de consumo (PRINGLE; THOMPSON, 2000). Estes benefícios econômicos se traduziriam na forma de vantagem competitiva com relação aos concorrentes que não executam ações sociais, representados por maiores lucros ou participação de mercado. Entretanto, o foco deste trabalho não está no Marketing Social Corporativo ou Marketing de Causas, com orientação para os negócios, mas sim no Marketing Social. Os principais envolvidos nos processos do Marketing Social são os órgãos públicos oficiais e as organizações do terceiro setor, os quais buscam sua utilização visando à geração de benefícios para a sociedade em geral ou segmento da mesma.

Segundo Andreasen (1994, p.110), o marketing social:

(...) é a adaptação de tecnologias do marketing comercial aplicadas em programas planejados para influenciar o comportamento voluntário de um público-alvo para gerar melhorias no bem estar pessoal, assim como no da sociedade da qual este público faz parte.

De outro ponto de vista, o Marketing Social é definido por Kotler (1978, p.15) como:

(...) o projeto, a implementação e o controle de programas que procuram aumentar a aceitação de uma ideia ou a prática social num grupo-alvo. Utiliza conceitos de segmentação de mercado, de pesquisa de consumidores, de configuração de ideias, de comunicações, de facilitação de incentivos e a teoria da troca, a fim de maximizar a reação do grupo-alvo.

Webster (1987, p.111), por sua vez, postula que:

(...) o marketing social compreende todas as atividades gerenciais envolvidas em conseguir a 
aceitação social de uma idéia ou causa. Essas atividades envolvem a definição genérica do conceito, a segmentação, a pesquisa de mercado e o projeto, a valorização, a distribuição e a comunicação de uma idéia ou causa específica.

Assim, o principal objetivo do Marketing Social é propiciar a mudança de comportamentos individuais ou sociais visando à melhoria de padrões de conduta em áreas como saúde pública, preservação do meio ambiente, segurança ou desenvolvimento de comunidades. Portanto, são exemplos de ações de Marketing Social as campanhas para redução do índice de mortalidade infantil (saúde pública), da estruturação da rede de vizinhos protegidos e de autoproteção (segurança pública), do descarte adequado do lixo eletrônico (meio ambiente) e da preservação da cultura e do modo de vida de comunidades tradicionais (ZENONE, 2006).

Percebe-se que o marketing social pode ser visto como função administrativa e, como tal, pressupõe a aquisição e a alocação de recursos, incluindo pessoas, materiais, tecnologia, dinheiro e informações. Uma organização sem fins lucrativos ou não governamental também opera num ambiente de um ou mais mercados e públicos como um mercado de doadores, um mercado de grupos de interesse, um mercado de opinião pública.

Chegar até o mercado desejado é de vital importância, por isso a comunicação aparece como o fator mais proeminente do marketing social. A propaganda e as relações-públicas são utilizadas para captação de recursos, para obtenção de simpatizantes e para adesão de patrocinadores. Por outro lado, a comunicação também é largamente utilizada para prestar informação, apresentar resultados, mobilizar voluntários e, sobretudo, disseminar ideias e promover mudanças (KOTLER, 1978).

Essas mudanças, segundo Kotler (1978, p.293), podem ser dos seguintes tipos:

a) Mudança Cognitiva: cujo propósito é informar a opinião pública, alterando, assim, seu nível de conhecimento a respeito de determinados assuntos. O Marketing Social acionaria seu sistema de pesquisas para identificar os grupos mais carentes de informações; para identificar seus hábitos de mídia e as predisposições comportamentais da audiência-alvo, de modo a subsidiar a elaboração das mensagens;

Exemplos:campanha para explicar o valor nutritivo de alimentos; campanha para chamar a atenção sobre o problema da velhice.

b) Mudança de Ação: visa alterar a atitude das pessoas ao induzir um número máximo dessas pessoas a realizar uma ação específica durante certo período. Este tipo de mudança apresenta maior grau de complexidade em relação à mudança cognitiva. A audiência-alvo deverá fazer um aprendizado para a execução de alguma coisa e isto envolve um custo para a pessoa. Mesmo que a sua predisposição seja favorável ela terá que ser deslocada da inércia.

Exemplos:campanha de vacinação em massa; campanha para atrair doadores de sangue; campanha para a prevenção do câncer; mutirão para a limpeza da rua.

c) Mudança no Comportamento: tem por objetivo ajudar as pessoas a modificar algum aspecto de seu comportamento, tendo em vista o bem-estar individual. A mudança comportamental lida com dinâmicas psicológicas mais arraigadas, requerendo, portanto, mais habilidades na sua condução.

Exemplos: programas para desencorajar o vício do fumo; campanhas contra o consumo de entorpecentes, bebidas alcoólicas, etc.

d) Mudança de Valor: as causas que procuram alterar crenças ou valores lidam com o tipo de mudança de maior grau de complexidade.

Exemplo: programa contra o racismo ou homofobia.

Normalmente as ações e as causas sociais exemplificadas anteriormente são efetuadas por órgãos governamentais, mas nada impede a execução destas por parte de empresas privadas com a utilização dos preceitos do Marketing Social Corporativo. Este trabalho, entretanto, limita-se ao recorte das ações de mudança independente dos desdobramentos destes no cenário dos negócios. 0 foco está nas trocas não monetárias viabilizadas pelo Marketing Social, analisadas pelos pressupostos da Lógica Dominada pelo Serviço.

Uma vez introduzidos os conceitos do marketing social e os preceitos básicos da Lógica Dominada pelo 
Produto e da Lógica dominada pelo Serviço, a próxima etapa consiste em explanar as ações sociais do programa "O Jovem e a Mobilidade" da BHTRANS, e identificar nelas as partes relacionadas ao marketing social e à Lógica dominada pelo Produto, para em seguida sugerir ações orientadas pela Lógica Dominada pelo Serviço, cujo ator beneficiário complementa a proposta de valor colocada pela BHTRANS pela integração de recursos e cocriação de valor.

\section{MÉTODO}

Para analisar o fenômeno em questão, foi adotada perspectiva descritiva de cunho qualitativo. $\mathrm{Na}$ pesquisa qualitativa 0 objeto em estudo é o fator determinante para a escolha do método e não o contrário (FLICK, 2004). A escolha pelo método qualitativo é justificada pelo interesse na avaliação pessoal dos atores presentes no fenômeno (VERGARA, 2005).

Com relação aos instrumentos de coleta de dados, foram empregadas a pesquisa documental e a entrevista semiestruturada com a coordenadora pedagógica do programa. Por pesquisa documental entende-se 0 uso de documentos oficiais e relatórios como fonte de dados. Neste estudo foram consultados relatórios de atividades divulgados pela empresa BHTRANS S/A referentes aos resultados do programa "O Jovem e a Mobilidade" no ano de 2013. A pesquisa nos relatórios de atividades buscou evidenciar quais ações foram realizadas com base na Lógica Dominada pelo Produto e quais com base na Lógica Dominada pelo Serviço.

Em uma entrevista semiestruturada, por sua vez, o tema da entrevista é comunicado ao entrevistado, assim como questões são utilizadas para direcionar suas respostas (VERGARA, 2005). A entrevista deste estudo foi realizada com a coordenadora pedagógica do programa "O Jovem e a Mobilidade" em novembro de 2014. 0 entrevistador direcionou perguntas que tinham como assunto a perspectiva da entrevistada quanto à participação dos alunos, aos resultados esperados, aos resultados obtidos até o momento e aos aspectos que precisariam de melhorias no programa. Na análise das respostas buscaram-se aspectos que remetem ao uso da Lógica Dominada pelo Serviço, tanto na operacionalização atual quanto nas melhorias consideradas necessárias. A seguir são expostos uma breve descrição do programa e os dados levantados na entrevista semiestruturada e na pesquisa documental.

\subsection{Ações em Marketing Social executadas no programa "O Jovem e a Mobilidade"}

O programa "O Jovem e a Mobilidade" é uma iniciativa permanente de educação para 0 trânsito promovido pela BHTRANS, órgão ligado à Prefeitura Municipal da cidade de Belo Horizonte que coordenada o trânsito e o transporte coletivo na cidade. 0 programa é destinado aos estudantes do ensino médio das escolas estaduais e particulares do município de Belo Horizonte na faixa etária de 18 a 25 anos.

Esses alunos são pedestres, ciclistas, passageiros do transporte coletivo por ônibus e grande parte torna-se motociclista ou motorista. O projeto tem o objetivo de conscientizá-los sobre o seu papel na mobilidade urbana sustentável, comportamentos que preservem a vida e o meio ambiente e os aspectos negativos e positivos das opções pelos modos de deslocamentos (GEDUC, 2013).

O programa realiza encontros, palestras, debates, exibição de filmes e gincanas nas escolas estaduais e particulares do município de Belo Horizonte que aderem ao programa. Para a realização do programa, a BHTRANS, por meio da Gerência de Educação para o Trânsito (GEDUC), elabora a lista de escolas que serão atendidas ao longo do ano. A meta do Programa é estabelecida de acordo com o número de alunos atendidos no ano anterior (GEDUC, 2013).

O processo para a realização do programa consiste inicialmente na aplicação de questionário para a pesquisa "Jovem e a Mobilidade", que tem como objetivo conhecer os meios de deslocamento utilizados pelos jovens e seu comportamento com relação aos fatores de risco para acidentes de trânsito. Em seguida são promovidos encontros presenciais com os alunos para apresentar os conceitos da mobilidade e tratar os fatores de risco, promoção de concurso de vídeos, além de cursos para formação dos professores. Ao final das atividades, é aplicada uma avaliação do programa pelos alunos, professores e equipe da GEDUC. Os dados da pesquisa de avaliação são tabulados e os resultados apresentados em novo encontro presencial com os alunos. 


\subsection{Entrevista semiestruturada}

A responsável pelo programa na BHTRANS afirmou em entrevista que os alunos sentem-se parte do processo, devido à realização deste processo de retroalimentação. Segundo a entrevistada, este processo é uma forma de diálogo com alunos e um momento importante para inseri-los no programa. 0 encontro presencial tem duração de 1 hora e 30 minutos com a apresentação dos resultados tabulados da pesquisa realizada no primeiro momento.

Nesse encontro presencial e durante a apresentação dos resultados da pesquisa, realizada previamente com os alunos, os resultados são utilizados para tratar fatores de risco. Esse encontro é um momento de diálogo com os alunos. A coordenadora do programa apontou que essa etapa de diálogo com os alunos é imprescindivel e nenhuma escola passa para a $2^{\mathrm{a}}$ etapa sem que o perfil dos alunos seja estudado.

A tabulação dos questionários aplicados nos alunos das escolas localizadas na periferia aponta para os resultados semelhantes: os principais fatores de risco apontados são velocidade, carona com alcoolizado e uso de celular ao volante. Após essa constatação, a etapa para aplicação do questionário poderia ser eliminada, porém a equipe da GEDUC acredita que a pesquisa é um instrumento importante para iniciar o diálogo com os alunos.

A entrevistada enfatiza novamente que "seria uma maneira para sensibilizá-los, pois são os resultados foram construídos com a participação deles. Com isso, eles se sentem parte do processo". Na tabulação dos resultados, fica evidenciada a diferença nos resultados das escolas públicas e particulares e, ainda, entre a escola particular localizada na periferia e na Zona Sul da cidade. A localização da escola altera a percepção de mobilidade, as necessidades de deslocamento e os fatores de risco.

Depois da palestra é realizada a avaliação do programa pelos alunos e eles ficam aptos a participar do concurso de vídeos. Quando o vídeo é selecionado, ele é inserido para apresentação e premiação no Seminário de Educação. Já foram realizados cinco Seminários de Educação com a participação das escolas de ensino médio que participaram do programa "O Jovem e a Mobilidade". A cada seminário são premiados os três melhores vídeos e entregue menção honrosa até a décima posição (GEDUC, 2103).

Segundo a entrevistada, outra parte importante do processo é a formação dos professores por meio de realização de oficinas para torná-los aptos a continuar a discussão dos conceitos de mobilidade na escola. Estas oficinas ocorrem de acordo com a disponibilidade de cada escola, e seu número aumenta a cada ano, formando cada vez mais professores. Um maior número de professores aumenta a probabilidade da mudança de comportamento dos alunos, que é uma das formas de aplicação do marketing social (KOTLER, 1978; ANDREASSEN, 1994).

\subsection{0 relatório de atividades GEDUC}

No relatório utilizado como fonte de dados para a pesquisa, a BHTRANS apresenta os resultados das atividades desenvolvidas pela GEDUC em 2013. Nele apresentam-se os dados quantitativos sobre o programa "O Jovem e a Mobilidade", dentro da seção "Ações Educativas Permanentes". Nesta seção, também são mostrados os resultados de outros programas, com o "Transitando Legal", o de palestras em empresas e instituições, e o de formação de operadores do transporte público.

Com relação ao programa "O Jovem e a Mobilidade", o relatório apresenta dados quantitativos sobre 0 número atendido de escolas e de estudantes, além do resultado de pesquisa sobre o nível de esclarecimento por parte dos estudantes atendidos. No relatório também é apresentado gráfico indicando o crescimento no número de atendidos pelo programa. Uma descrição sucinta do conteúdo do relatório, relativo ao programa "O jovem e a Mobilidade", é mostrada a seguir.

O relatório inicia descrevendo o programa, o seu objetivo, o público-alvo e o método empregado para conscientizar o público-alvo sobre seu papel na construção de uma cidade mais humana no que se refere às opções de deslocamento. No ano de 2013 foi lançado o concurso de vídeos, cujo tema "O trânsito e o valor da vida" foi explorado por estudantes participantes do programa. No relatório não há informações sobre os ganhadores do concurso, assim como não há divulgação do conteúdo dos vídeos premiados e sua contribuição para a análise dos resultados obtidos com as palestras, os debates e as gincanas. 
Em seguida o relatório mostra o número de escolas e estudantes atendidos mensalmente no ano de 2013. Percebe-se uma redução do número de atendimentos no mês de julho, devido ao período de recesso em algumas escolas. Nos meses de janeiro e dezembro, por se tratar de período de férias escolares, não há atividade do programa. $O$ número de atendimentos por mês é exposto na Tabela 1.

Tabela 1: Número de escolas e alunos atendidos pelo programa mensalmente

\begin{tabular}{c|c|c}
\hline Mês & No de escolas & No de alunos \\
\hline janeiro & 0 & 0 \\
\hline fevereiro & 9 & 815 \\
\hline março & 10 & 1551 \\
\hline abril & 14 & 1744 \\
\hline maio & 23 & 1912 \\
\hline junho & 23 & 2392 \\
\hline julho & 6 & 456 \\
\hline agosto & 17 & 2423 \\
\hline setembro & 20 & 3175 \\
\hline outubro & 24 & 2803 \\
\hline novembro & 22 & 3993 \\
\hline dezembro & 0 & 0 \\
\hline Total & $\mathbf{1 6 8}$ & $\mathbf{2 1 2 6 4}$ \\
\hline
\end{tabular}

Fonte: Relatório GEDUC-BHTRANS, 2013.

De acordo com o relatório, o resultado do ano de 2013 superou a meta planejada de atender $60 \%$ dos estudantes da rede de ensino da cidade de Belo Horizonte. A meta planejada representava um total de 19.000 alunos, entre a rede de ensino pública e privada, e foi superada em 11,9\%, com 21.264 atendimentos. Para 0 ano de 2014, a meta é atender 22.120 alunos, que representam 70\% dos estudantes da rede de ensino (GEDUC, 2013). Como instrumento de verificação de resultado, o programa aplica avaliação aos alunos com o objetivo de verificar o nível de esclarecimento sobre a mobilidade urbana correta. Os resultados desta avaliação são expostos na Tabela 2.

Tabela 2: Percepção de esclarecimento sobre mobilidade urbana correta

\begin{tabular}{c|c}
\hline \hline $\begin{array}{c}\text { Plenamente } \\
\text { esclarecido }\end{array}$ & 90,5 \\
\hline $\begin{array}{c}\text { Parcialmente } \\
\text { esclarecido }\end{array}$ & 9,2 \\
\hline Nao esclarecido & 0,3 \\
\hline
\end{tabular}

Fonte: Relatório GEDUC-BHTRANS, 2013.

Por fim, o relatório faz uma comparação do número de atendimentos do ano de 2013 com anos anteriores. Por meio do Gráfico 1, é possível perceber o crescimento constante no número de atendimentos. 0 maior crescimento, entretanto, ocorreu entre os anos de 2012 e 2013, cujo aumento foi de $177,4 \%$. 
Gráfico 1: Número de alunos atendidos anualmente pelo programa

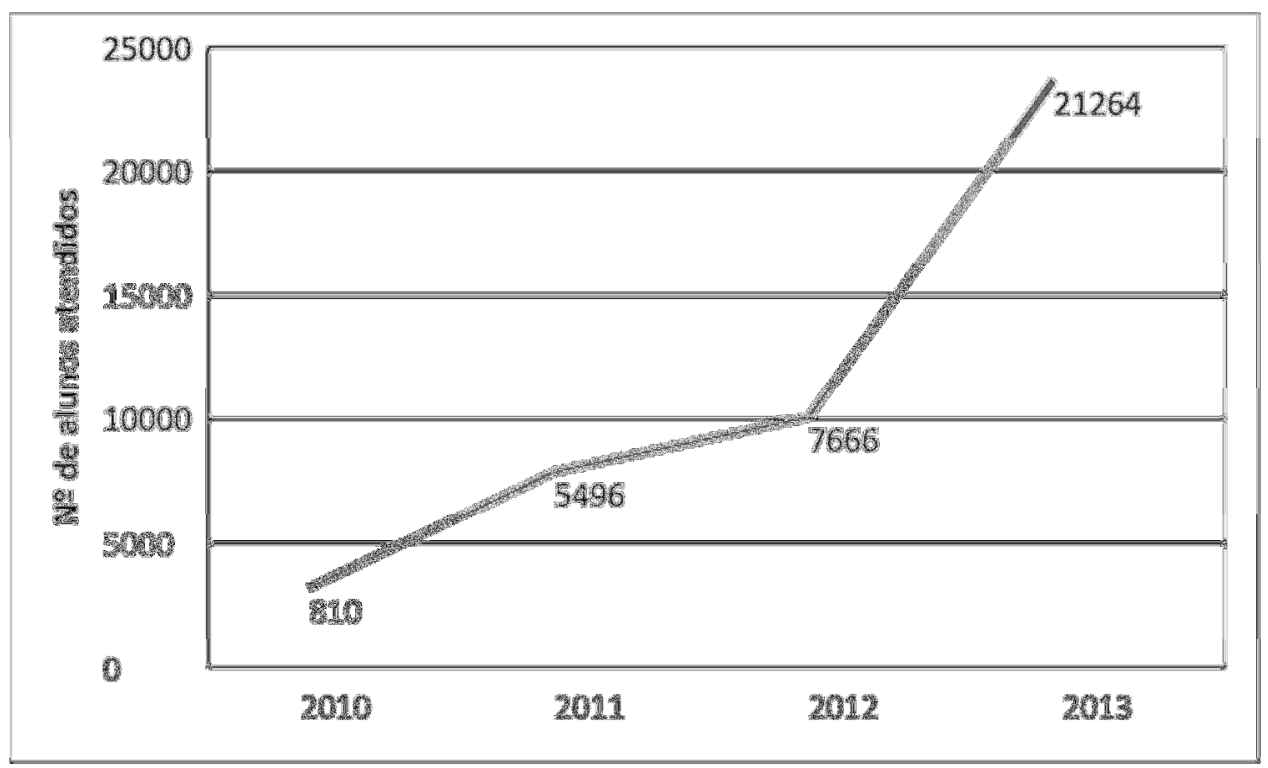

Fonte: Relatório GEDUC-BHTRANS, 2013.

Os dados presentes no relatório mostram que o programa está, ano a ano, crescendo em abrangência. Em termos de eficiência, o programa superou a meta de atendimentos para o ano de 2013. 0 resultado da avaliação de esclarecimento indica que o método utilizado fez com que quase todos os estudantes participantes declarassem ter entendido a proposta do programa. Assim, pode-se inferir que as ações do programa "O Jovem e a Mobilidade" podem ser classificadas como pertencentes ao domínio do Marketing Social. As declarações da coordenadora pedagógica do programa, entretanto, apresentam informações que não foram inseridas no relatório, que seriam importantes na perspectiva da Lógica Dominada pelo Serviço. Este é um dos assuntos tratados no tópico a seguir.

\section{DISCUSSÃO}

Primeiramente, relembram-se alguns pontos destacados anteriormente. Na LDS, toda troca entre atores é uma troca de serviço por serviço, sendo o serviço a aplicação de conhecimentos e habilidades no benefício da contraparte ou em benefício próprio. Além de provedor, um ator pode assumir o papel de beneficiário e de recurso, operável ou operante. Firmas não entregam valor, mas sim "propostas de valor", sendo valor definido como um incremento na viabilidade, ou seja, na chance de sobrevivência e bem-estar. Valor sempre é singularmente e fenomenologicamente determinado pelo beneficiário.

No início da discussão, toma-se a sétima premissa da Lógica Dominada pelo Serviço: (P7) a firma não entrega valor, apenas propostas de valor. No programa da BHTRANS, o valor proposto seria o aumento na chance de bem-estar e principalmente sobrevivência, dado a grande incidência de mortes por acidentes de trânsito no país, por meio da adoção voluntária de hábitos que visam à segurança e ao bem-estar. Porém, como postulado na premissa P10, é preciso que o beneficiário participe do processo de cocriação de valor para que este seja pleno.

De acordo com os dados obtidos, a coordenadora pedagógica do programa considera 0 aluno do ensino médio participante como beneficiário, propondo-lhe um valor que pode trazer bem-estar. Ela considera 0 aluno também como um recurso operante ao utilizar as respostas dos questionários e os conteúdos dos vídeos do concurso como recurso para aperfeiçoar aplicações futuras do programa. Assim, percebe-se que 0 aluno participa indiretamente da coprodução e da cocriação do valor proposto pelo programa.

As declarações da coordenadora afirmam também a importância da integração de recursos. Como citado na premissa P9, todos os atores são integradores de recursos, e a BHTRANS faz esse papel ao integrar os recursos materiais e financeiros da entidade com os recursos advindos dos participantes na forma de 
sugestões escritas e em vídeo. Os participantes também fazem esta integração, ao adotar comportamentos em mobilidade urbana que respeitem as normas de trânsito. No final, todos os atores ganham.

A premissa P4 também está presente no discurso da coordenadora do programa. Segundo esta premissa, os recursos operantes representam a fonte fundamental de vantagem competitiva. Obviamente 0 programa social não compete com outros programas sobre mobilidade, mas com as dificuldades criadas pelo ambiente em que os estudantes se locomovem: ruas, avenidas, espaços para ciclistas e pedestres, normas de trânsito, veículos particulares e coletivos, sinalizações e comportamento de condutores.

Os recursos operantes disponiveis na BHTRANS são as pessoas, como a coordenadora e sua equipe, os estudantes e os professores. Para superar as dificuldades, os profissionais da BHTRANS aplicam seus conhecimentos e habilidades em ações que podem trazer vantagem sobre os problemas. Os estudantes, como beneficiários e recursos operantes, auxiliam na coprodução do programa, juntamente com os professores, que após qualificação participam da consolidação do valor proposto. A integração destes recursos operantes, juntamente com os recursos operáveis, como salas, impressos, projetores e computadores, viabiliza a criação de valor.

Entretanto, no Relatório de Atividades do GEDUC não há indicações sobre a importância da participação de alunos e professores no valor proposto pelo programa. 0 relatório segue a Lógica Dominada pelo Produto, em que os alunos e os professores são considerados consumidores do produto ofertado. No relatório as informações fornecidas enfatizam o progresso no número de alunos e professores participantes ano a ano, mostrando a eficiência na aplicação de recursos.

Esta visão, baseada na LDP, traz algumas limitações, pois não divulga ao grande público o valor cocriado, nem a participação efetiva dos alunos e dos professores na criação de valor, ou seja, a importância desses atores no processo para o aumento da viabilidade do sistema por meio do aumento da chance de sobrevivência e bem-estar. O Relatório de Atividades, como instrumento de divulgação, poderia ser o principal veículo para a disseminação da importância da cocriação de valor. No tópico a seguir são colocadas mais algumas sugestões, na forma de aplicações gerenciais, baseadas na LDS.

\section{PROPOSTAS DE AÇÕES ORIENTADAS PELA LÓGICA DOMINADA PELO SERVIÇO}

$\mathrm{Na}$ LDS, todas as trocas são trocas de serviço por serviço. Ao propor o serviço de conscientização para uma mobilidade segura aos jovens estudantes do ensino médio, estes precisam retribuir a iniciativa pública, demonstrando a efetiva assimilação do treinamento e conscientização. Segundo os autores deste trabalho, o serviço retribuído pelos estudantes consistiria no benefício da mobilidade segura na condução de automóveis e motocicletas. Então, a primeira proposta é verificar se a troca está realmente se efetivando, monitorando o comportamento no trânsito destes estudantes.

A segunda proposta está relacionada ao conteúdo do relatório. As imagens e os dados presentes no documento se relacionam exclusivamente à comparação entre 0 planejado e 0 executado pela equipe da BHTRANS. Informações importantes declaradas pela coordenadora pedagógica do programa não estão presentes no relatório. $O$ relatório poderia incluir informações a respeito da importância da participação dos alunos e dos professores, ressaltando as mudanças, as adaptações e as correções efetuadas com base nas propostas dos participantes.

Em parte, os processos de coprodução são divulgados na forma dos concursos de vídeo, por exemplo, mas os processos de cocriação de valor poderiam ser incluídos. Como citado pela coordenadora, é importante sensibilizar o aluno mostrando o resultado de sua participação no resultado final.

A terceira proposta está relacionada com a premissa P10: o valor é unicamente e fenomenologicamente determinado pelo beneficiário. Seria conveniente o levantamento deste valor determinado pelo beneficiário, indo além da informação sobre o sentimento de esclarecimento por parte do aluno. Informações sobre o valor cocriado pelo aluno, quando este está no papel de beneficiário, são importantes para a determinação dos resultados do programa. 0 método para o levantamento deste valor pode ser elaborado conjuntamente com acadêmicos pesquisadores do tema.

Um exemplo é o estudo acadêmico feito por McColl-Kennedy et al. (12) sobre os estilos de práticas de cocriação de valor por clientes de hospitais em tratamento de câncer. Os autores pressupõem que clientes são 
atores ativos, com diferentes estilos de cocriação de valor, que estão inseridos num sistema social e que possuem potencial de aprender, adaptar e fazer escolhas baseadas em percepções. Segundo os autores, na área da saúde, dependendo do papel percebido pelos pacientes, eles desempenham atividades e interações pessoais diferentes, que por sua vez impactam tanto em seu estilo de cocriação de valor quanto no resultado terapêutico efetivamente obtido.

As implicações gerenciais do estudo, segundo McColl-Kennedy et al. (2012), são relacionadas ao fato de que, mesmo sendo providos com as mesmas propostas de valor, os pacientes podem integrar recursos de formas diferentes, perceber seu papel de forma diferente e cocriar valores diferentes. De acordo com os resultados do estudo, pacientes com maior engajamento à cocriação de valor apresentaram maior qualidade de vida durante o tratamento e por isso este tipo de estilo deveria ser incentivado.

Por fim, caso seja possibilitado o levantamento do valor cocriado pelo cliente, propõe-se a inclusão nas metas do programa de educação permanente 0 aumento deste valor cocriado pelos participantes do programa, não só para aumentar o engajamento, mas também para aumentar a assimilação de boas práticas de mobilidade, contribuindo para o aumento da segurança e do bem-estar da população envolvida.

\section{CONSIDERAÇÕES FINAIS}

O objetivo principal deste trabalho foi analisar o programa social "O Jovem e a Mobilidade" da BHTRANS do ponto de vista da Lógica Dominada pelo Serviço. Esta análise mostrou que intuitivamente a coordenação do programa adota a premissa da Lógica Dominada pelo Serviço sobre a importância atribuída à participação do aluno na coprodução das atividades do programa. Este fato indica que o aluno não é visto como um mero receptor de valor entregue, mas também como recurso operante, valioso para a efetivação da proposta de valor do programa. Porém, esse aspecto é abordado de forma superficial, sem o suporte teórico da LDS. A superficialidade impede a implantação de práticas elaboradas com o suporte teórico da Lógica Dominada pelo Serviço, as quais poderiam levar a um entendimento mais detalhado do processo de adoção das premissas do programa social pelos alunos participantes do programa.

Por outro lado, observou-se com maior frequência pontos de interseção do programa com a Lógica Dominada pelo Produto. Esses pontos são evidenciados principalmente no conteúdo do Relatório de Atividades. As informações divulgadas remetem à questão da eficiência quantitativa do programa, comparando os resultados atingidos com o planejado. Dá-se ênfase à eficiência e não à eficácia.

Percebe-se também que as informações no relatório colocam a BHTRANS como a "firma" que produz sozinha o valor, e os alunos como os "consumidores", que devem ser em maior quantidade a cada ano. Verificou-se também que existem muitas informações importantes, relacionadas à LDS, que não são divulgadas no relatório, como as mudanças no programa elaboradas com base nos resultados dos concursos de vídeos.

Assim, conclui-se que o programa social "o Jovem e a Mobilidade" ainda segue os preceitos da Lógica Dominada pelo Produto, sendo que conceitos da Lógica Dominada pelo Serviço são abordados pela coordenadora do programa. Entretanto, devido à falta de suporte teórico, os conceitos abordados não são utilizados como insumos para melhorias no programa, nem como suporte teórico para divulgação de resultados.

Por isso, as sugestões gerenciais orientadas pela LDS referem-se principalmente ao conteúdo do relatório. A principal proposta sugere a mensuração do valor cocriado pelos alunos participantes, sua divulgação no relatório e a adoção do objetivo de aumentar este valor a cada ano. Esta sugestão remete à outra: 0 acompanhamento do comportamento dos alunos quando estes se tornam condutores de veículos.

A mensuração do valor cocriado ainda é controversa na LDS. Não há um consenso sobre a forma conveniente de sua operacionalização. Apesar disso, na opinião dos autores deste trabalho, a principal contribuição da Lógica Dominada pelo Serviço é ampliar o campo teórico científico das trocas para além dos limites econômicos. Na LDS não é obrigatória a presença de valor econômico no objeto ou no fenômeno estudado. Basta a troca de serviço, na forma de benefícios e criação de valor, para que o fenômeno se encaixe nas premissas teóricas e possa ser explicado.

Assim, este trabalho pretende como benefício indireto trazer a discussão, acadêmica e prática, de um novo enfoque para o gerenciamento de projetos públicos de intervenção na realidade cotidiana dos indivíduos, a partir da adoção de um enfoque centrado na criação de valor proposto pela Lógica Dominada pelo Serviço. 


\section{LIMITAÇÕES E SUGESTÕES DE ESTUDOS}

Além da questão do método para a mensuração do valor cocriado, as limitações deste estudo são representadas: (i) pelo fato de o estudo ser transversal e refletir o fenômeno somente em dado momento; (ii) pelo fato de o estudo abordar um caso somente, seus resultados e constatações não podem ser generalizados para outros fenômenos semelhantes; (iii) pelo fato de as sugestões apresentadas serem válidas somente para 0 programa analisado. Com relação às sugestões de pesquisas sobre o tema, estas remetem às propostas de ações gerenciais orientadas pela LDS apresentadas anteriormente.

Para pesquisas posteriores, sugere-se o acompanhamento dos alunos do ensino médio que participaram do programa, pelo acesso ao histórico de seu prontuário junto do Departamento de Trânsito, após a habilitação. Sugere-se, também, o acompanhamento da base de dados de acidentes para verificar a ausência de envolvimento em acidentes de trânsito. Um histórico com ausência de infrações e ausência de registros de acidentes representaria a efetividade do programa e a cocriação de valor por parte do participante do programa.

Outra sugestão é o estudo, por meio de grupos de foco, das formas de cocriação de valor por parte dos participantes explorando possíveis perfis de cocriação, e a influência da participação na coprodução do programa no valor cocriado. Em outras palavras, o estudo buscaria entender como se dá o processo de coprodução, quando o participante está no papel de recurso; e de cocriação de valor, quando o participante está no papel de beneficiário.

\section{REFERÊNCIAS}

ANDREASSEN, A. R. Social Marketing: its definition and domain. Journal of Public Policy \& Marketing. V. 13, N. 01, Spring 1994.

BRAMBILLA, F. R.; DAMACENA, C. Lógica Dominante do Serviço em Marketing: Estudo dos Conceitos e Premissas Aplicados à Educação Superior Privada na Perspectiva Docente. Revista Brasileira de Marketing, v. 10, n. 3, p. 151-176, 2011

FLICK, U. Uma introdução à pesquisa qualitativa. Porto Alegre: Artmed, 2004.

GEDUC: Relatório de Atividades. BHTRANS. Prefeitura de Belo Horizonte, 2013.

HUNT, S. Foundations of Marketing Theory: toward a general theory of marketing. M.E. Sharpe, New York, 2002.

KOTLER, P. Marketing para organizações que não visam lucro. São Paulo: Atlas, 1978.

LUSCH, R.F.; VARGO, S.L. Service-Dominant Logic: premises, perspectives, possibilities. Cambridge University Press, 2014.

McCOLL-KENNEDY, J. R.; VARGO, S. L.; DAGGER, T. S.; SWEENEY, J. C.; van KASTEREN, Y. Health care customer value cocreation practice styles. Journal of Service Research. May 2012. Disponível em: http://jsr.sagepub.com/content/early/2012/04/29/1094670512442806.

MORAES, M. B.; COSTA, B. K. Co-criação de valor e perspectiva da lógica dominante: um estudo em uma empresa do setor aeronáutico. Revista Brasileira de Gestão e Desenvolvimento Regional, v. 9, n. 2, p. 262279, 2013.

PIOVESAN, A.; TEMPORINI E. R. Pesquisa exploratória: procedimento metodológico para o estudo de fatores humanos no campo da saúde pública. Revista Saúde Pública, v.4, n. 29, p.318-325, 1999.

PRINGLE, H.;THOMPSON, M. Marketing Social: Marketing para Causas Sociais e a Construção das Marcas. MAKRON Books, 2000.

VARGO, S.L.; LUSCH, R.F. Service-Dominant Logic: what is, what is not, what it might be. In LUSCH, R.F.; VARGO, S.L. (Ed.). The Service Dominant Logic of Marketing: dialog, debate and directions. M.E. Sharpe. London, 2006, p. 43-56. 
VARGO, S.L.; LUSCH, R.F. Service-Dominant Logic: continuing the evolution. Journal of the Academy of Marketing Science. V.36, n.01, p.1-10, 2008.

VERGARA, S. C. Métodos de pesquisa em Administração. São Paulo: Atlas, 2005.

WEBSTER, F. E. Aspectos sociais do marketing. São Paulo: Atlas, 1987.

WIELAND, H.; POLESE, F.; VARGO, S. L.; LUSCH, R. F. Toward a service (eco)system perspective on value creation. International Journal of Service Science, Management, Engineering, and Technology. v.03, n.03, july-september 2012, p.12-25.

ZENONE, Luiz. Marketing Social. São Paulo: Thompson Learning, 2006. 